Thorax (1950), 5, 325.

\title{
THE MAXIMUM BREATHING CAPACITY TEST
}

\author{
BY \\ JOHN L. D'SILVA AND DAVID MENDEL \\ From the Physiology Department, the London Hospital Medical College
}

(RECEIVED FOR PUBLICATION JULY 24, 1950)

Since the introduction of this test by Hermannsen (1933), the measurement of maximum breathing capacity (M.B.C.) on different groups of subjects has been reported on several occasions (for example, Gray and Green, 1945 ; Baldwin, Cournand, and Richards, 1948 ; Wright, Yee, Filley, and Stranahan, 1949 ; and Gilson and Hugh-Jones, 1949).

Most investigators have performed this test with a spirometer, such as is used for metabolic rate determinations, from which the non-return valves and carbon dioxide absorbing canister have been removed. The instructions issued to the subjects have varied. Baldwin instructed his subjects to "breathe as quickly and as deeply as possible: the accent on speed." The instructions given by Gray and Green are too lengthy and complicated for general use. Gilson and Hugh-Jones instructed the subjects to breathe "as deep as you can, as fast as you can." They modified these instructions to some extent by exhorting the subjects, during the first few moments of the test, to make greater efforts to increase the depth of breathing, or the rate, or both the rate and the depth as deemed necessary by an experienced observer who knew the conditions of breathing likely to give the highest value.

In the course of a pilot experiment it was noted that subjects chose widely varying respiration rates when told to "breathe as deep as you can, as fast as you can." Not only was there a wide variation in the rate chosen by different subjects, but the same subject chose different rates at successive attempts. It was also noticed that, if the rate chosen was above approximately 55 respirations per minute (R.P.M.), so violent were the movements of the water in the spirometer that often it was aspirated into the connecting tubes and no observations were possible.

We have therefore investigated the maximum ventilatory capacity (M.V.C.), at controlled rates of breathing, of a group of medical students and laboratory workers whose ages ranged from 19 to 32 years. We use the term maximum ventilatory capacity when we refer to the maximum number of litres per minute that a subject can breathe at a controlled rate of respiration.

\section{THE EXPERIMENT}

The apparatus used was a Knipping type spirometer (6 litre bell) from wsich the air-circulating pump and the carbon dioxide absorber were removed. The frictional resistance to movement of the bell was such that, when the spirometer bell was full of air, a $40 \mathrm{~g}$. load would empty it. If the water in the spirometer was slightly agitated, a $30 \mathrm{~g}$. load emptied the bell. For an experiment the spirometer system was 
filled with air. The subject was connected to the apparatus by an anaesthetic mask which, because of its pneumatic cushion, formed an air-tight seal when pressed against the subject's face. The test was performed with the subject standing, and the face mask was tested for leaks with each subject. This procedure had the added advantage of instructing the subject in the importance of maintaining an air-tight seal. The subject was instructed to breathe through his mouth, and then the following tests were performed.

Vital capacity determinations were practised until it was certain that the subject thoroughly understood what was required of him. Three vital capacity measurements were then made in succession. These measurements, together with a further three made at the end of the series of tests, were averaged to determine the subject's vital capacity.

The maximum ventilation test was carried out in time to a metronome. Each beat of the metronome was the signal for beginning either inspiration or expiration. The metronome was first set at 60 per minute, so that the respiratory rate was 30 per minute. In this experiment the subject was instructed to breathe as deeply as possible in time to the metronome. During the performance of the test the subject, irrespective of his performance, was exhorted to keep in time with the metronome and to breathe as deeply as possible. The maximum ventilation test was repeated at 40 and 50 R.P.M. with intervals of 10 minutes between the tests.

After 10 minutes' rest, three more vital capacity determinations were made.

The spirometer tracings were taken on a drum moving at five times the usual rate for metabolic rate measurements, and with the help of a time scale the precise rate of breathing was determined. All the subjects achieved a rate of breathing within 1 or 2 R.P.M. of that set by the metronome.

The over-breathing was continued for periods of 12 to 24 seconds in different experiments. The tidal air was measured directly, and the M.V.C. in litres per minute at a known rate of breathing was calculated from the breaths taken during the last 12 seconds of over-ventilation. The readings were corrected to $37^{\circ} \mathrm{C}$. at the ambient pressure. During this last period of 12 seconds the subjects seemed to have reached their maximum tidal air. Some subjects produced their maximum tidal air from the first breath; all of them did so within 12 seconds.

\section{RESULTS}

Table I gives a measure of the physical characteristics of the group of subjects used. The group is comparable in physical proportions with that investigated by

TABLE I

Physical Characteristics of 15 Male Students and Laboratory Workers

\begin{tabular}{|c|c|c|c|c|c|c|}
\hline \multicolumn{4}{|c|}{ Physical Characteristic } & Mean & S.D. & Range \\
\hline Age (years) & . & $\cdots$ & $\cdots$ & 23.7 & \pm 2.9 & $19-32$ \\
\hline $\begin{array}{l}\text { Ht. (cm.) } \\
\text { Wt. (kg.) } \\
\text { Body surface }\end{array}$ & $\begin{array}{cc}\ddot{e} & \cdots \\
\dot{e} \text { (sq. metres) }\end{array}$ & $\ddot{*}$ & $\begin{array}{l}\cdots \\
\cdots \\
\cdots\end{array}$ & $\begin{array}{c}180.0 \\
71.2 \\
1.88\end{array}$ & $\begin{array}{l} \pm 7.7 \\
\pm 8.2 \\
\pm 0.15\end{array}$ & $\begin{array}{r}168-194 \\
57-89 \\
1.68-2.2\end{array}$ \\
\hline
\end{tabular}

Baldwin and others (1948). In Table II are the details of the results obtained on each individual. In only one case (13) did an increase in respiratory rate from 30 to 40 lead to a decrease in breathing capacity. For each subject, the M.V.C. at 50 R.P.M. was higher than at either of the two slower respiratory rates tried. 
TABLE II

Vital Capacity and Maximum Ventilatory Capacity (M.V.C.) of a Group of 15 MaLe STUDENTS AND LabORATORY WORKerS

\begin{tabular}{|c|c|c|c|c|c|c|c|c|}
\hline \multirow{2}{*}{\multicolumn{3}{|c|}{ Subject }} & \multirow{2}{*}{$\begin{array}{c}\text { Vital } \\
\text { Capacity } \\
\text { (ml.) }\end{array}$} & \multicolumn{3}{|c|}{$\begin{array}{l}\text { M.V.C. (1./min.) at } \\
\text { Respiration Rates of }\end{array}$} & \multicolumn{2}{|c|}{ Predicted M.B.C. } \\
\hline & & & & 30 & 40 & 50 & Wright et al.*| & Baldwin et al. $\dagger$ \\
\hline $\begin{array}{l}1 \\
2 \\
3 \\
4 \\
5 \\
6 \\
6 \\
7 \\
8 \\
9 \\
10 \\
11 \\
12 \\
13 \\
14 \\
15\end{array}$ & 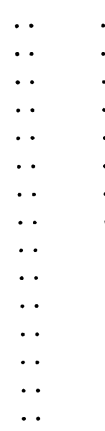 & 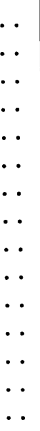 & $\begin{array}{l}4,100 \\
5,250 \\
5,180 \\
5,000 \\
5,150 \\
5,820 \\
4,800 \\
6,000+ \\
6,000+ \\
4,950 \\
5,880 \\
5,860 \\
4,850 \\
6,000+ \\
6,400\end{array}$ & $\begin{array}{r}96 \\
110 \\
121 \\
118 \\
100 \\
108 \\
113 \\
144 \\
122 \\
121 \\
124 \\
140 \\
143 \\
150 \\
165\end{array}$ & $\begin{array}{l}114 \\
134 \\
139 \\
148 \\
155 \\
137 \\
141 \\
172 \\
164 \\
145 \\
174 \\
175 \\
120 \\
180 \\
187\end{array}$ & $\begin{array}{l}126 \\
144 \\
166 \\
170 \\
172 \\
176 \\
176 \\
178 \\
184 \\
194 \\
200 \\
210 \\
220 \\
221 \\
286\end{array}$ & $\begin{array}{l}154 \\
171 \\
170 \\
163 \\
168 \\
167 \\
166 \\
165 \\
165 \\
165 \\
167 \\
159 \\
165 \\
165 \\
167\end{array}$ & $\begin{array}{l}120 \\
126 \\
139 \\
137 \\
134 \\
146 \\
125 \\
138 \\
143 \\
134 \\
156 \\
159 \\
133 \\
147 \\
142\end{array}$ \\
\hline \multicolumn{3}{|c|}{ Average .. } & & 125 & 152 & 188 & 165 & 132 \\
\hline
\end{tabular}

* Prediction formula (Wright et al., 1949): M.B.C. (in litres/minute) $=197.5-(1.36 \times$ age in years)

+ Przdiction formula (Baldwin et al., 1948): M.B.C. (in litres/minute) $=[86.5-(0.522 \times$ age in years) $\times$ body surface in $\mathrm{m}^{2}$.

The average value for the M.V.C. is included at each rate. The mean value for the M.V.C. of our group at 50 R.P.M. is significantly higher than the mean value for their M.B.C. predicted on the basis of the two available prediction formulae, namely those of Baldwin and others (1948) and of Wright and others (1949). We have evidence from other experimental work that the M.V.C. at 50 R.P.M. of our student group does not represent their M.B.C. The M.V.C. reaches a maximum, with our apparatus, at about 65 R.P.M. At this rate it was about 15 litres per minute greater than at 50 R.P.M.

Control Experiments.-The spirometer bell was calibrated against the standard recording paper and differences in readings were negligible $( \pm 1.2 \%)$.

No special steps were taken to reduce the frictional resistances in our instrument, so it is most probable that the discrepancy between our results and those published previously is not to be explained in terms of an unduly low frictional resistance.

Reproducibility of Results.-Gilson and Hugh-Jones (1949) found that there was a considerable variation in an individual's performance in successive experiments performed on any one day and from day to day. Table III shows the results of observations made on nine subjects using two different spirometer bells. Each horizontal line records the M.V.C. in successive determinations made on one day on the subject under conditions shown in column 3. Ten minutes' rest was allowed between determinations. The results are clearly closely reproducible; it seems that when the respiration rate is controlled the variability on any particular day is small. 
TABLE III

REPRODUCiBILITY OF DETERMINATIONS OF M.V.C.

\begin{tabular}{|c|c|c|c|c|c|c|c|c|}
\hline \multirow{2}{*}{ Subject } & \multirow{2}{*}{\multicolumn{6}{|c|}{ M.V.C. (litres per min.) }} & \multicolumn{2}{|c|}{ Conditions of Experiment } \\
\hline & & & & & & & No. Breaths/Min. & Bell \\
\hline $\begin{array}{r}1 \\
2 \\
4 \\
5 \\
7 \\
9 \\
10 \\
11 \\
12\end{array}$ & $\begin{array}{l}126 \\
107 \\
118 \\
133 \\
111 \\
149 \\
111 \\
174 \\
210\end{array}$ & $\begin{array}{l}140 \\
110 \\
115 \\
132 \\
114 \\
138 \\
113 \\
168 \\
206\end{array}$ & $\begin{array}{l}130 \\
117 \\
130 \\
110 \\
146 \\
113 \\
162 \\
210\end{array}$ & 126 & 127 & 129 & $\begin{array}{l}50 \\
30 \\
30 \\
30 \\
30 \\
30 \\
30 \\
40 \\
40\end{array}$ & $\begin{array}{l}\text { A } \\
\text { A } \\
\text { A } \\
\text { A } \\
\text { A } \\
\text { A } \\
\text { A } \\
\text { B } \\
\text { A }\end{array}$ \\
\hline
\end{tabular}

The Degree of Co-operation of the Subject.-One group of normal subjects were all enthusiastic to perform the test, and there was a spirit of keen competition amongst them to record as high a figure in the M.V.C. test as possible. To investigate this factor as a possible reason for our high results, a set of experiments was carried out on control hospital patients at 50 R.P.M. and with the same apparatus. These subjects were attending the out-patient department of the hospital for the treatment of conditions other than disease of the lungs. In each case the physician in charge of the case pronounced the lungs normal. Table IV shows their physical

TABLE IV

Maximum Ventilatory Capacity of OUt-patients with Normal Chests

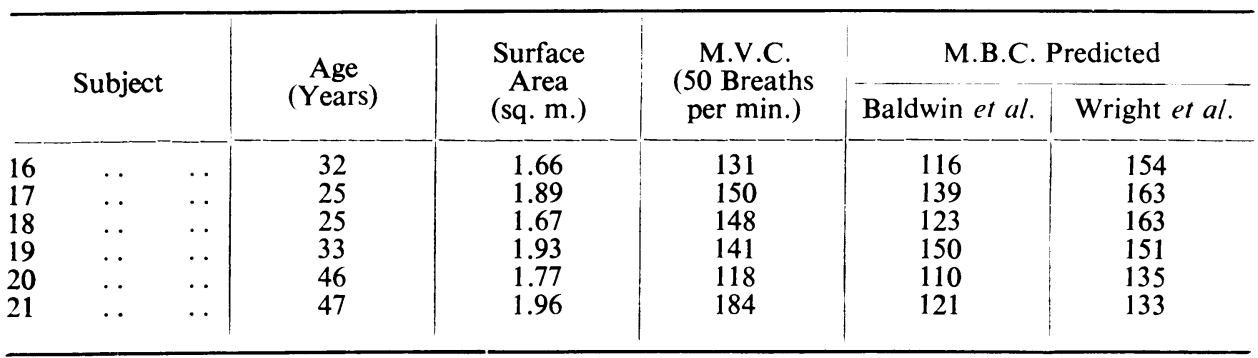

For columns 4 and $5, P=0.1$. For columns 4 and $6, P=0.7$.

proportions, their performance at a respiratory rate of 50, and their M.B.C. calculated on the basis of the formulae of Baldwin and others and of Wright and others. The sets of figures in columns 4 and 5 , and 4 and 6 , are not significantly different. If it is assumed that the M.B.C. of these subjects is 15 litres a minute greater than their M.V.C. at 50 R.P.M. (as we have found to be the case with the student group), their M.B.C.s would be adequately represented by the values predicted by the formula of Wright and his colleagues. It is likely therefore that the M.V.C. of the control hospital patients is significantly lower than that of the students, and it is possible that the difference is to be explained by the lack of wholehearted co-operation by the hospital patients. 
Spirometer Records in Response to Rapid Movement of the Bell.-The spirometer used was not designed to record rapid respiratory rates, so its performance at high rates of movement was tested by using a pump with a constant stroke volume to simulate rapid breathing. The inlet and outlet of the pump were both connected to the spirometer.

Fig. 1 shows the apparent output of a pump which had a stroke volume of $2,800 \mathrm{ml}$. and was manually operated. It can be seen that the recorded volume of the pump output gradually increased with increasing rate up to 55 R.P.M. when

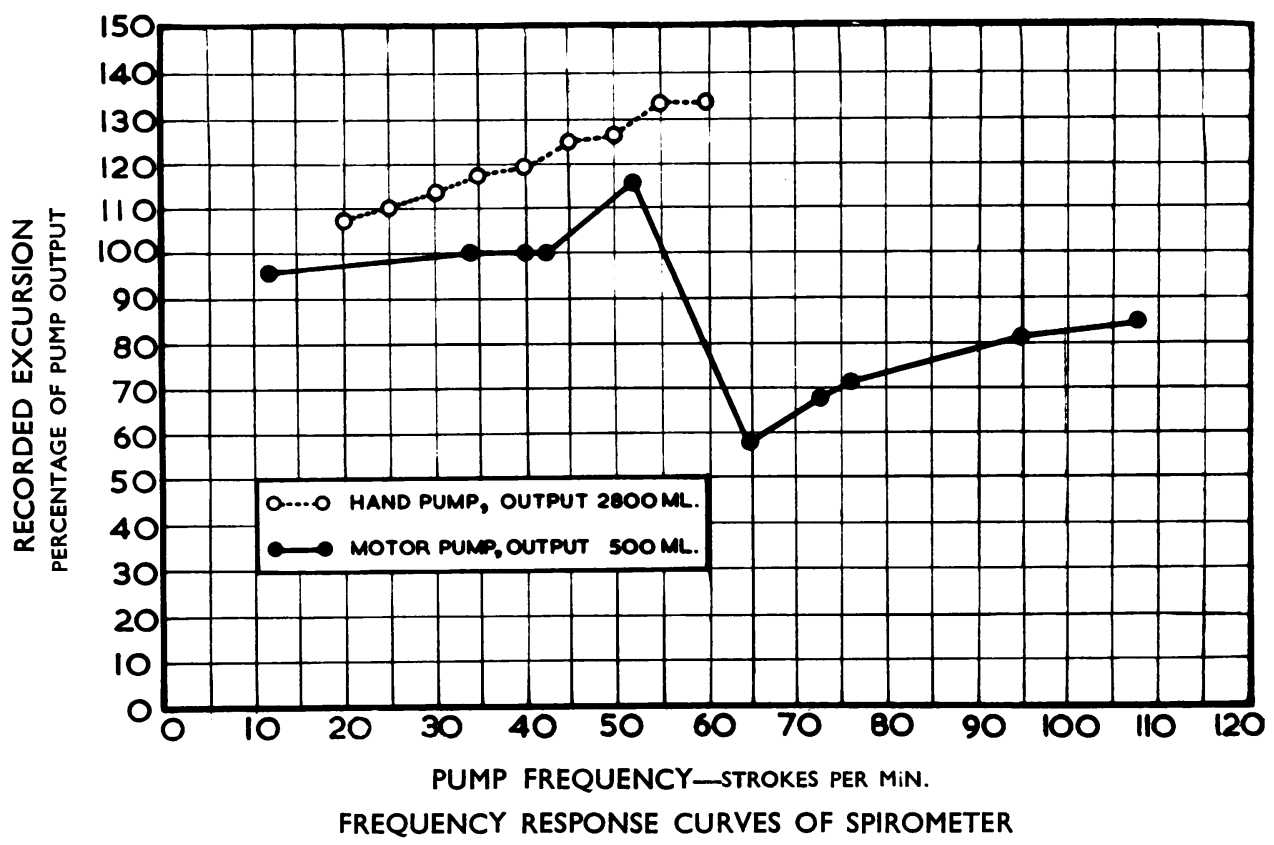

Fig. 1.-Recorded excursion of spirometer bell expressed as the percentage of the actual output of the pump supplying it at various " respiratory" rates.

it was $134 \%$ of the true pump output. At 65 R.P.M. water was aspirated into the connecting tubes and no readings were possible at this or higher rates of pumping. Fig. 1 also shows the recorded output of a pump with a stroke volume of $500 \mathrm{ml}$. With this small stroke volume no water was aspirated, and it can be seen that at rates up to 40 R.P.M. the pump output was faithfully recorded. At 45 R.P.M. it started to rise, reached $115 \%$ of the true pump output at 52 R.P.M., fell abruptly to $57 \%$ of the true pump output at 65 R.P.M., and subsequently recorded only slightly more accurately. It was found that the inertia of the moving parts of the spirometer at rapid " respiration" rates caused pressure changes to occur within the bell, which set in oscillation the U-shaped column of water shown in section in Fig. 2. The water column has a natural resonant frequency which depends upon its length, and at " respiratory " rates in the region of the natural resonant frequency the amplitude of the oscillation is so great that the movements of the bell are affected. 


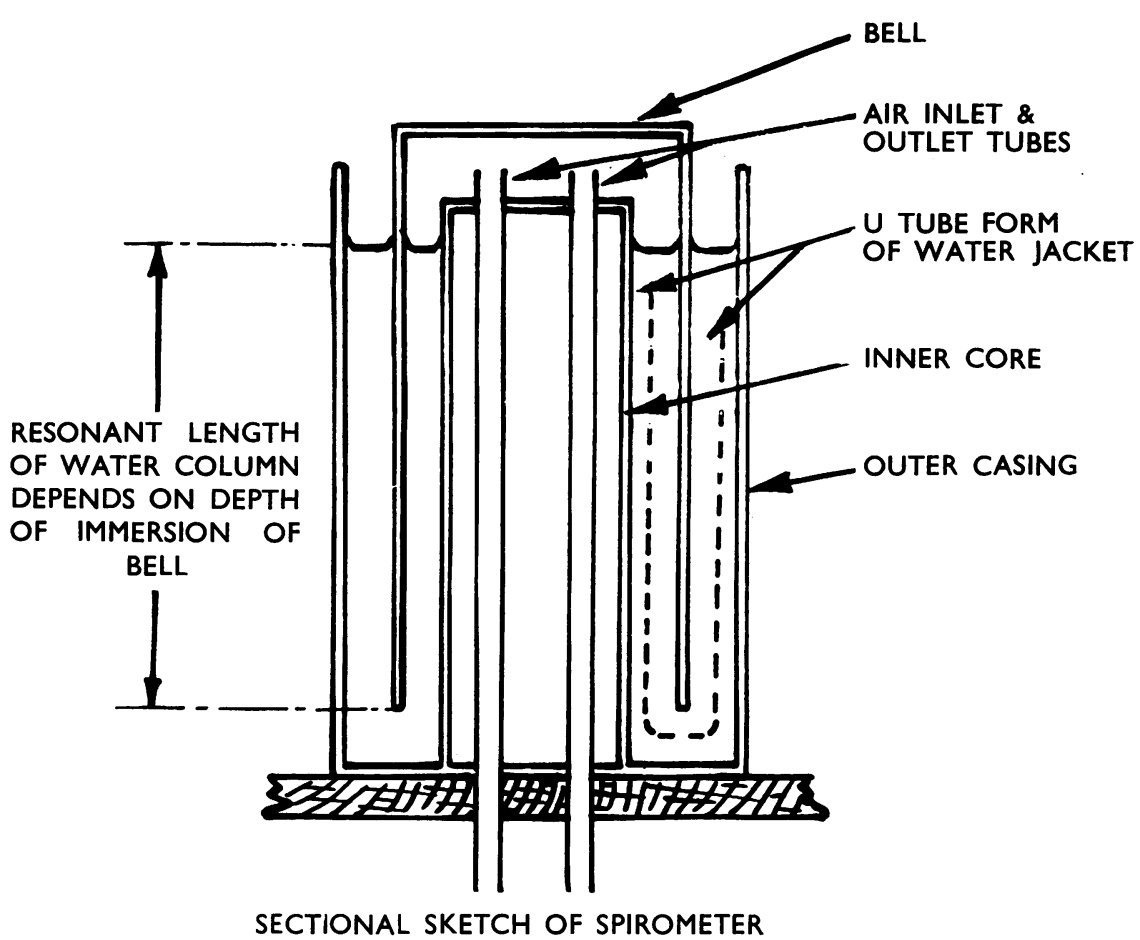

FIG. 2.-Sketch of spirometer to show how the water jacket effectively forms a " $U$ tube " in section, the length of the $U$ tube being determined by the depth of immersion of the bell.

The phase relationships between the oscillating column and the moving bell determine whether an increase or a decrease in the recorded volume occurs.

It seems fairly certain that on our instrument results from the M.V.C. at rates above 30 R.P.M., although repeatable, are liable to serious errors. We think that this is probably a factor in producing the high figures we have obtained at 50 R.P.M., but it is not possible to correct our figures, because the precise manner in which the bell responds to rapid respiratory rates depends on (1) the inertia of the moving parts of the spirometer; (2) the depth to which the bell is submerged; (3) the respiratory rate at which the determination is carried out; and (4) the form of the respiratory airflow curve. A correction could be made in our experiments for (1) and (3), as the inertia is constant and the respiratory rate has been controlled. The depth to which the bell is submerged and the respiratory airflow curve will vary from subject to subject, and it is not possible to correct for these.

Table V shows the tidal air of our subjects at 30, 40, and 50 R.P.M. At the bottom of the table the mean tidal air for each rate is given.

The vital capacity cannot be repeated more than about 12 times in a minute. Respiratory rates greater than this can only be achieved by decreasing the depth of each breath, and as the rate is increased the depth must decrease further. The mean value for the tidal air in our subjects at 30 R.P.M. was $274 \mathrm{ml}$. higher than 
TABLE $\mathrm{V}$

Tidal Air of Students Performing Test of M.V.C. at 30, 40, and 50 R.P.M.

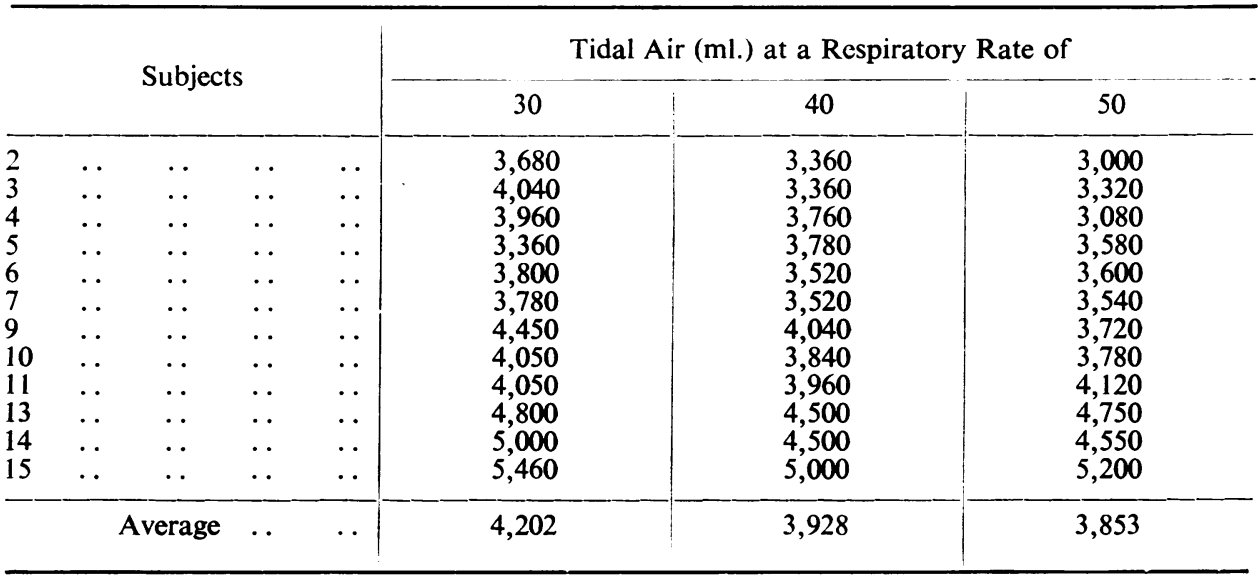

that obtained at 40 R.P.M. This is a significant difference. Between 40 and 50 R.P.M., however, the tidal air decreased by only $75 \mathrm{ml}$. This decrease is not significant, and in fact seven of the subjects had a greater tidal air at 50 than they had at 40 R.P.M.

Provided the subjects co-operated fully - and, from the high values obtained and our subjective impressions we feel that they did-the absence of a significant decrease in tidal air between 40 and 50 R.P.M. can only be explained on the basis of an apparatus error. It can be seen from Fig. 1 that a positive error is to be expected at 50 R.P.M.

\section{Discussion}

A group of normal medical students produced higher figures for M.V.C. than a group of normal hospital patients, and we suggest that the difference is due to the lack of wholehearted co-operation on the part of the latter group. Further, as it is not possible to assess accurately the degree of co-operation given by the subject, the test loses much of its usefulness when the maximum ventilatory or breathing capacity is just below the lower limit of the normal range.

The M.B.C. test is used to estimate the efficiency, as a group, of the various mechanical factors concerned in ventilation, and, in a normal person, it is grossly in excess of the number of litres per minute he would breathe during the most strenuous exercise (Robinson, 1938). The M.B.C. is thus similar to other tests of organ function in that the ventilatory mechanism is overloaded and its response to this overload is measured. In view of the fact that the ventilatory mechanism is overloaded in a test of M.V.C. at 30 R.P.M. (because the tidal air is less than the vital capacity), the same information can be obtained from a determination of the M.V.C. at this rate as can be obtained from a determination of the M.B.C., provided that normal values are known for this rate. The figures obtained for the M.V.C. at 30 R.P.M. of our student group were $82 \%$ of their predicted M.B.C. based on Wright's formula. 
We suggest that, when a spirometer is used for any form of maximum breathing test, a determination of M.V.C. at 30 R.P.M. is substituted for a determination of M.B.C. for the following reasons.

(1) Spirometers, as usually constructed, are not suitable instruments with which to determine the M.B.C. of individuals who are allowed to choose their own rate of breathing, because they do not record faithfully the tidal air at rates of breathing above 30 R.P.M. This error is necessarily present in all spirometers to a greater or lesser extent, and it cannot be allowed for readily.

(2) Determinations of the M.V.C. at a rate of breathing which is below that which evokes resonance in the moving system (30 R.P.M. with our instrument) will give a more accurate estimate of ventilatory function than will a determination of the M.B.C. which is subject to errors the precise magnitude of which cannot be assessed.

The figures in Table III show that the M.V.C. at controlled rates of breathing is highly repeatable. From the published work it can be seen that this "repeatability" is far higher than that obtained in M.B.C. determinations.

(3) All subjects so far tested have been able to follow a metronome within one or two R.P.M. When the rate is controlled the subject is no longer in doubt as to whether he is to emphasize the rate or the depth factor.

\section{SUMMARY}

Two causes of error in the determinations of maximum breathing capacity and maximum ventilatory capacity have been examined. (1) The degree of co-operation given by a subject cannot be estimated accurately. A student group giving full co-operation gave significantly higher figures in the maximum ventilatory capacity test than those obtained from control hospital patients. (2) An apparatus error, inherent in all spirometers, which cannot easily be allowed for becomes important at high respiratory rates.

It is proposed that the maximum ventilatory capacity at 30 respirations per minute be determined instead of the maximum breathing capacity. This procedure would have the following advantages: (a) It would enable the test to be carried out in the least inaccurate range of the spirometer. (b) The results thereby obtained are more reproducible than those obtained in maximum breathing capacity determinations.

We wish to thank for their co-operation Drs. Kenneth Perry and N. Lloyd Rusby, under whose care the hospital patients were, and the patients and medical students who acted as subjects.

\section{REFERENCES}

Baldwin, E. deF., Cournand, A., and Richards, D. W. (1948). Medicine, Baltimore, 27, 243. Gilson, J. C., and Hugh-Jones, P. (1949). Clin. Sci., 7, 185.

Gray, J. S., and Green, E. L. (1945). U.S. Army Air Force School of Aviation Medicine Project No. 449: Report No. 1.

Hermannsen, J. (1933). Z. ges. exp. Med., 90, 130.

Proctor, D. F., and Hardy, J. B. (1949). Bull. Johns Hopk. Hosp., 85, 253.

Robinson, S. (1938). Arbeitsphysiologie, 10, 251.

Wright, G. W., Yee, L. B., Filley, G. F., and Stranahan, A. (1949). J. thorac. Surg., 18, 372. 